\title{
Investigation into the Flow Properties of Coarse Solid Fuels for Use in Industrial Feed Systems
}

\author{
James M. Craven, Jim Swithenbank, and Vida N. Sharifi \\ Energy and Environmental Engineering Research Group (EEERG), Department of Chemical and Biological Engineering, \\ University of Sheffield, Mappin Street, Sheffield S1 3JD, UK
}

Correspondence should be addressed to James M. Craven; james.craven@sheffield.ac.uk

Received 16 February 2015; Revised 8 May 2015; Accepted 17 May 2015

Academic Editor: Alberto Di Renzo

Copyright (C) 2015 James M. Craven et al. This is an open access article distributed under the Creative Commons Attribution License, which permits unrestricted use, distribution, and reproduction in any medium, provided the original work is properly cited.

\begin{abstract}
Material feeding and handling systems have been cited as one of the most common causes of process downtime where thermochemical conversion processes are concerned. New and emerging fuels come in a variety of forms, and if such fuels are to be deployed widely it is imperative that material feeding and handling systems are designed appropriately. This study proposes an approach for designing material feeding and handling systems for use with coarse solid fuels. The data obtained from this study indicates particle size to be one of the key issues affecting the flowability of bulk solids further to the uniformity in particle shape. Coarse bulk solid samples were shown to flow more freely than their milled and pulverised counterparts, generating higher degrees of flowability. The results from this study were also applied to a new feed system used for feeding solid fuels to high pressure processes named the Hydraulic Lock Hopper. In this study the Hydraulic Lock Hopper demonstrated the feeding of wood pellets, torrefied spruce pellets, and ground anthracite coal grains against a pressure of 25 barg in two modes of operation. Energy savings compared to conventional lock hopper systems were recorded in the region of $80 \%$.
\end{abstract}

\section{Introduction}

The number of biomass fed systems has increased dramatically in recent years and with this much has been learnt about the dynamics of operating a biomass fired plant. Due to the apparent similarities to coal plants, many mistakes have been made in the development and utilisation of biomass fuels in thermochemical conversion processes, not least where material handling and feeding are concerned $[1,2]$.

The assessment of a material's properties is of paramount importance when handling bulk solids. Where combustion and gasification systems are concerned, material feeding and handling systems have been cited as one of the most common causes of process downtime, especially when handling new and emerging fuels $[3,4]$. More often than not, problems have arisen due to inadequately designed and sized equipment and where biomass species have been assumed to behave in a convenient and stable manner like their coal counterparts. Though fundamentally solid fuels, biomass species behave far differently to coals and generally have a greater risk attached with them when they are handled due to their higher reactivity $[5,6]$. Wood dust ignites at much lower temperatures than coal dust and requires a significantly lower amount of energy for ignition [7].

But aside from the difference in inherent safety when handling such fuels in their milled form, attention should be focused on how parent materials behave in their coarse bulk form. Fuels are present in their coarse bulk form for the majority of their lifetime, and therefore systems should be designed appropriately to handle fuels in this form to avoid feeding and handling problems. Much work has been carried out regarding the handling of fine and milled materials, most notably that carried out by Jenike and Janssen [8-11]. However, comparative work regarding coarse materials is sparse, especially when it comes to the assessment of physical flow properties. More recently, work regarding the flow properties of a number of biomass fuels has been reported [12-15], and it is proposed that, for coarse, irregularly shaped biomass materials arching occurs not because of material cohesion but because of tensile strength due to particle interlocking [16]. 
TABLE 1: Particle and bulk density of each material.

\begin{tabular}{lcc}
\hline Material & $\begin{array}{c}\text { Particle density } \\
(\mathrm{g} / \mathrm{mL})\end{array}$ & $\begin{array}{c}\text { Bulk density } \\
(\mathrm{g} / \mathrm{mL})\end{array}$ \\
\hline Wood pellets & $1.26 \pm 0.006$ & $0.651 \pm 0.004$ \\
Torrefied wood pellets & $1.27 \pm 0.004$ & $0.677 \pm 0.002$ \\
Ground anthracite & $1.35 \pm 0.004$ & $0.731 \pm 0.001$ \\
Torrefied wood chips & $0.43 \pm 0.005$ & $0.170 \pm 0.001$ \\
Milled wood pellets & $1.53 \pm 0.005$ & $0.344 \pm 0.007$ \\
Pulverised coal & $1.51 \pm 0.010$ & $0.542 \pm 0.007$ \\
\hline
\end{tabular}

However, still no well-defined design procedure for storage and feeding systems currently exists for coarse materials, and consequently problems remain in this area.

The aim of this study is to scale up and apply the same design procedure used for fine materials to coarse bulk solids and to determine the physical properties of a range of new and emerging fuels key to the design of storage and feeding devices. Physical properties of coarse bulk solids will be compared to fine and milled materials, and such fuels will be assessed alongside a new feeding system used for feeding solid fuels to high pressure processes, named the Hydraulic Lock Hopper (HLH).

\section{Materials and Methods}

2.1. Materials. Six fuels were tested: wood pellets $(\varnothing 6 \mathrm{~mm})$, torrefied wood pellets $(\varnothing 8 \mathrm{~mm})$, ground anthracite coal grains $(\sim 10 \mathrm{~mm})$, torrefied wood chips $(20-50 \mathrm{~mm})$, milled wood pellets (200-600 $\mu \mathrm{m})$, and pulverised bituminous coal $(\sim 220 \mu \mathrm{m})$. Table 1 provides an overview of all of the fuels in terms of their particle and bulk density.

The wood pellets used are commercially available and were procured from CPL Distribution Ltd. They are made from chemically untreated residues from the wood processing industry and comprise a physically stable low ash pellet conforming to the standard ENplus A1. The pellets described were used as the starting material for the milled wood pellets and were milled using a hammer mill fitted with a trapezoidal screen of size $1.5 \mathrm{~mm}$. The coarsely ground anthracite coal grains were also procured from CPL Distribution Ltd. and have an average particle size of approximately $10 \mathrm{~mm}$. The coal grains are characteristic of anthracite and display a submetallic lustre. Both the torrefied wood pellets and wood chips were made available by the Energy Centre of the Netherlands (ECN), were made from spruce, and were torrefied at a temperature of $260^{\circ} \mathrm{C}$ for approximately 40 minutes. The pulverised coal was of bituminous rank and was sized approximately $220 \mu \mathrm{m}$. The bituminous coal was as received and required no further processing.

2.2. Methods. The approach used for assessing coarse bulk solids physical properties was adapted from that proposed by Jenike for hopper design incorporating fine materials [11, $17,18]$. The two principal tests required to be carried out for hopper design according to this procedure are the material shear test and wall friction shear test. Such tests are used to determine the unconfined yield stress $\left(\sigma_{c}\right)$, material flow function $\left(\mathrm{ff}_{c}\right)$, angle of internal friction $(\varphi)$, effective angle of internal friction $(\delta)$, and the kinematic angle of wall friction $\left(\phi_{w}\right)$. From these properties a hopper is able to be reliably sized and designed and the discharge rate from the hopper assessed. The semi-included angle of the hopper slope $(\theta)$ and the hopper flow factor (ff) are able to be determined from the effective angle of internal friction and the kinematic angle of wall friction. The stress corresponding to the critical condition for flow or no flow $\left(\sigma_{\text {crit }}\right)$ is able to be determined from the material flow function and hopper flow factor, and the minimum outlet diameter $(B)$ is able to be determined from the critical flow condition, the semi-included hopper angle, and the bulk density $\left(\rho_{b}\right)$ of the material.

As the work carried out by Jenike largely concerned fine materials, the associated apparatus, namely, the Jenike Shear Cell, is scaled accordingly. Where coarse materials are concerned, such apparatus is unable to be used [11]. Equipment using the same principle applied to fine materials was used in this case but of an order of magnitude greater in size.

2.2.1. Material Shear Test. Two types of annular shear testers were used. A large scale $\varnothing 1 \mathrm{~m}$ annular shear tester shown in Figure 1 was used in order to assess the wood pellets, torrefied wood pellets, torrefied wood chips, and ground anthracite coal, and a Brookfield Powder Flow Tester (PFT) fitted with a $\varnothing 15 \mathrm{~cm}$ shear cell was used in the case of the milled wood pellets and pulverised bituminous coal. Both shear testers operate in the same manner and consist of an annular tray, a cupped lid, and a torque sensor/load cell. Material is loaded into the annular tray, evenly levelled, and then a cupped lid of known mass is applied. A load is applied to the shear cell lid which acts to consolidate the material to a known and repeatable bulk density. Material is then sheared to failure through the rotation of the annular tray around a central point at a constant velocity.

Due to the scale of the apparatus used, the lowest consolidation stress used in this study (approximately $1.0 \mathrm{kPa}$ ) was limited by the inherent mass of the shear cell lid. Consolidation stresses greater than this were chosen and spaced to ensure shear planes in different regions of the bulk material being sheared were generated.

2.2.2. Wall Friction Shear Test. As with the material shear test, two types of wall friction shear tester were used. A large scale $\varnothing 28 \mathrm{~cm}$ annular shear tester shown in Figure 1 was used in order to assess the wood pellets, torrefied wood pellets, torrefied wood chips, and ground anthracite coal, and as with the material shear tests, a Brookfield PFT fitted with a $\varnothing 15 \mathrm{~cm}$ shear cell was used to assess the milled wood pellets and pulverised bituminous coal.

The principle of both wall friction shear testers is the same; however, they differ slightly in how they are operated. In the case of the Brookfield PFT, the operational procedure is similar to that carried out for the material shear test. However, in place of the cupped lid used to measure the interparticle friction, an annular sample of wall material is fitted. Material is loaded into the same annular shear cell used for the material shear tests, levelled, and the annular sample of wall material 

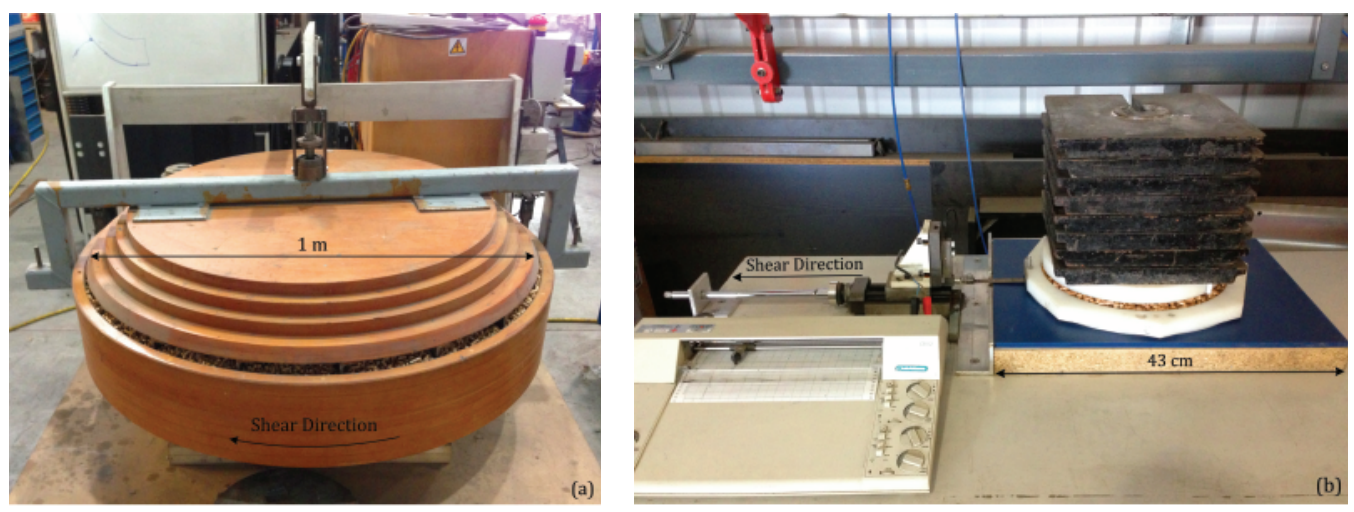

FIGURE 1: Large scale annular shear tester (a) and large scale wall friction tester (b) used for measuring coarse bulk solids.

is applied to the material at a known load. The shear cell containing the bulk solid is rotated at a constant velocity and in turn the material is sheared by the sample of wall material.

The large scale linear wall friction tester shears the bulk solid in a single direction. It is comprised of a circular ring and lid, a bracket, and a mechanical shearing arm. The bracket and shearing arm are connected and attached to the circular ring via a load cell which measures the shear stress generated. The circular ring is placed on top of a sample of wall material and a known mass of a bulk solid is placed inside the ring. A lid of known mass is then placed on top of the bulk solid and in turn a normal load is applied to the lid to create a stress normal to the bulk solid. The shearing arm is engaged and the bulk solid is sheared against the sample of wall material.

The general wall shear principle detailed above for both cases can be used for a broad range of wall materials. In this study stainless steel, mild steel, and TIVAR 88 were assessed in relation to all six of the stated bulk solids. TIVAR 88 is a low friction lining material commonly implemented in hoppers handling cohesive bulk solids. It acts to reduce phenomena such as arching and ratholing.

2.3. Hydraulic Lock Hopper Operational Overview. The HLH embodies an alternative system to conventional lock hoppers for feeding solid fuels to high pressure processes. Initial work with the HLH is detailed in [19] where it was shown that the primary advantage of the system is that it is able to operate with a far lower energy requirement than a conventional lock hopper.

The HLH is comprised of two hoppers, equal in volume, running in series, and separated by a valve. In addition to this principal valve, a pipe runs external to both of the hoppers and acts to connect and separate the two via an additional valve. A high pressure water pump is connected to the top of the two hoppers and is used in the compression stage of the feeding operation. No pressurising gas is needed to operate the HLH and the only work required in the compression stage is that to pump water against a back pressure.

The initial configuration of the HLH is such that the top hopper is at atmospheric pressure and the bottom hopper is at a desired operating pressure. Fuel is fed to the top hopper and is sealed at atmospheric pressure. The principal valve connecting the two hoppers is opened and fuel is fed to the bottom hopper. During this stage, pressure equalisation takes place and both hoppers are contained at an equal pressure higher than that of the atmosphere but lower than that of the operating pressure. The principal valve is then shut and the valve in the external pipe connecting the two hoppers is opened. Water is pumped to the top hopper against a back pressure and acts to displace the gas in the top hopper at high pressure. Fuel does not become contaminated with water during this stage as the fuel being fed is located in the bottom hopper during the compression phase. Water is only ever present in the top hopper during the compression phase and therefore does not contaminate the fuel being fed. As the water level in the top hopper increases, the pressure in both the head space above the liquid level and the bottom hopper containing the fuel increases. The water pump is disengaged once the desired operating pressure is reached and the valve in the external pipe is closed. A valve at the exit of the bottom hopper is opened and the fuel is fed to the high pressure process with no net change in pressure. The water is then drained from the top hopper and the process is able to start anew. This describes Mode 1 . The HLH can be operated in an additional mode: Mode 2.

The operational procedure for Mode 2 is broadly similar to Mode 1, with the exception that only the top hopper is required. When the primary valve is opened, the fuel is fed directly to the process at pressure. The difference between the two modes comes in the compression stage. Mode 2 requires the top hopper to be completely filled with water, thus displacing a maximum of gas at high pressure, whereas the volume of water required to be pumped in Mode 1 is approximately equal to the void space present between the fuel prior to feeding. This typically varies between 40 and $60 \%$ for most solid fuels [20], and so on average only half of the top hopper has to be filled with water when operating in Mode 1 . Mode 1 has the advantage that a minimum of energy is required to feed as a lower volume of water is required to be pumped, and Mode 2 has the advantage that no gas at high pressure is vented and in turn wasted. 


\section{Results and Discussion}

3.1. Material Shear Tests. A linear relationship of increasing shear stress with increasing normal stress is shown in Figure 2 for all materials. This trend is observed due to the bulk strength of each of the materials increasing when the normal load applied is increased. However, a distinction can be made between the coarse materials (wood pellets, torrefied pellets, ground anthracite, and torrefied wood chips) and the fine materials (milled wood pellets and pulverised coal). That is, as the consolidation stress increases, the stress required to shear both of the fine materials increases where the same normal load is applied. This is not found to be the case when shearing the bulk of the coarse materials and thus where the consolidation stress is increased, the stress required to shear the materials is maintained broadly constant where the normal load applied is also maintained constant.

The reason for both fine materials requiring a larger shear stress to shear the material at the same normal stress but where the consolidation stress is increased is due to material cohesion and an increased level of cohesion. Materials cohesion is generally found to increase as mean particle size decreases due to interparticle forces representing the dominant forces in the bulk material [17, 18]. Such interparticle forces are found to be greater than competing gravitational and inertial forces and act to increase material cohesion. In this case, interparticle forces are largely present in the form of electrostatic forces and van der Waals forces.

Applying Mohr stress analysis to the plots shown in Figure 2 allows pairs of values of the unconfined yield stress and the consolidation stress to be measured and plotted to generate a material flow function. A material flow function for each material is shown in Figure 3 and the broad classification of each material flowability is stated in Table 2. Generally flowability can be classified into the following categories: freeflowing ( $\mathrm{ff}_{c}>10$ ), easy-flowing $\left(4<\mathrm{ff}_{c}<10\right.$ ), cohesive $\left(2<\mathrm{ff}_{c}<4\right)$, very cohesive $\left(1<\mathrm{ff}_{c}<2\right)$, or does not flow $\left(\mathrm{ff}_{c}<1\right)[18]$.

Coarse materials can generally be considered to be easyflowing when dry. This is due to inertial and gravitational forces being the dominant forces in the bulk material. In the case of all of the coarse materials, the material flow function indicates that a low stress is required to generate incipient flow and deformation of the material even after a significant consolidation load has been applied. In the case of both the milled wood pellets and pulverised coal, a strong linear relationship between consolidation stress and unconfined yield stress is observed. Both materials are indicated to be cohesive with the milled wood pellets being observed to be more cohesive than the pulverised coal. This can be attributed to the relative particle size variation and the respective particle shape. In the case of the milled wood pellets, a broader range of particle sizes is present and further to this a broad range of particle shapes. The milled wood pellets are largely made up of needle-like structures interspersed with finer material. It is supposed that it is these needle-like structures that interact to form more stable bulk structures which in turn require a larger stress to create a deformation. Comparatively, the pulverised coal is seen to be broadly uniform in size and shape.
TABLE 2: Broad classification of the material flow function and definition of flowability for each material.

\begin{tabular}{lcc}
\hline Material & $\begin{array}{c}\text { Material flow } \\
\text { function }\left(\mathrm{ff}_{c}\right)\end{array}$ & $\begin{array}{c}\text { Flow function } \\
\text { category }\end{array}$ \\
\hline Wood pellets & 6.12 & Easy-flowing \\
Torrefied wood pellets & 24.0 & Free-flowing \\
Ground anthracite & 6.37 & Easy-flowing \\
Torrefied wood chips & 6.49 & Easy-flowing \\
Milled wood pellets & 2.91 & Cohesive \\
Pulverised coal & 3.72 & Cohesive \\
\hline
\end{tabular}

In addition to the material flow function, Mohr stress circle analysis allows both the effective angle of internal friction and the angle of internal friction of each material to be determined. Figure 4 shows that in all cases the effective angle of internal friction is maintained broadly constant at all consolidation stresses, ranging between $35^{\circ}$ and $40^{\circ}$. Where lower consolidation stresses are applied, a slight deviation is noted with the effective angle of internal friction being raised by a couple of degrees. However, as the consolidation stress increases past a given point, little or no change is noted. A similar trend is observed in the case of the angle of internal friction. However, in this case where lower consolidation stresses are applied the angle is reduced by a couple of degrees.

Both trends are observed in all materials and both angles are observed to be broadly similar in all cases. This is with the exception of the milled wood pellets which highlights a greater degree of interparticle friction, reflected by the marginally higher effective angle of internal friction recorded.

3.2. Wall Friction Shear Tests. Due to the HLH being predominantly manufactured out of mild steel and the HLH incorporating water during its operation, the mild steel sample was tested when being both dry and wet. The kinematic angle of wall friction is a pivotal parameter when determining the angle at which a material will flow and in the case of the HLH, when determining the hopper half angle required to generate flow. Assessing the mild steel wall sample when wetted provides a more accurate value for design in the case of the HLH.

Figure 5 highlights a general trend of decreasing friction angle with increasing normal stress where low normal stresses prevail $(<2 \mathrm{kPa})$. Where normal stresses greater than $2 \mathrm{kPa}$ are generated, the kinematic angle of wall friction is seen to stay broadly constant for all materials and with all wall material samples. Figure 5 therefore indicates that where low normal stresses prevail, a steeper hopper is required to prompt the flow of material for all materials. Further to this Figure 5 indicates that a greater shear force is required to displace the bulk material when the mild steel sample is wetted compared to when it is dry, and in turn a larger wall friction angle is recorded.

In the majority of cases either the TIVAR 88 or mild steel sample require the smallest shear force to be imparted to generate displacement. Therefore, hoppers constructed from either of these materials are required to be the least steep 

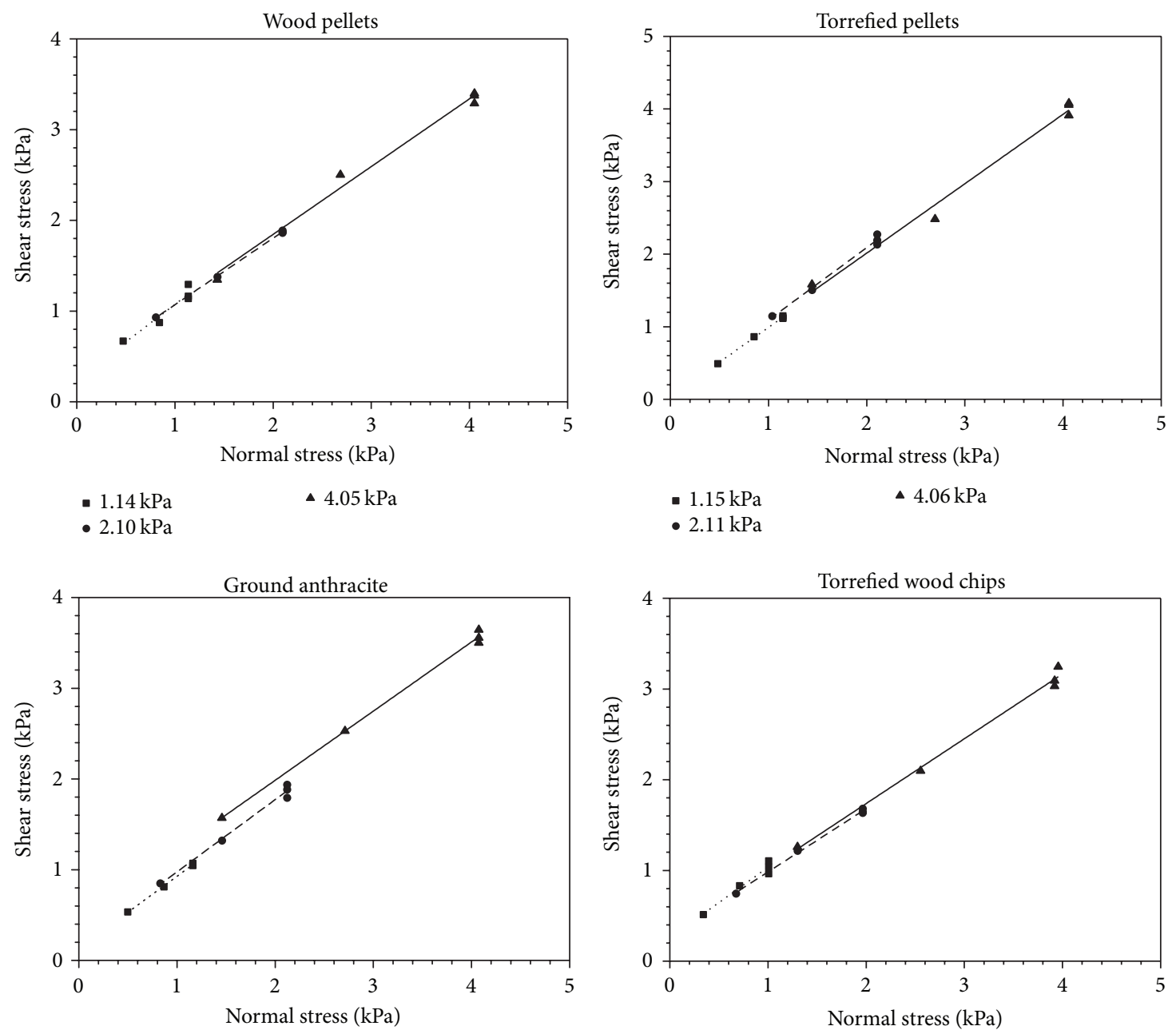

- $1.16 \mathrm{kPa}$

$\Delta 4.08 \mathrm{kPa}$

- $1.00 \mathrm{kPa}$

$\Delta 3.92 \mathrm{kPa}$

- $2.12 \mathrm{kPa}$

- $1.97 \mathrm{kPa}$
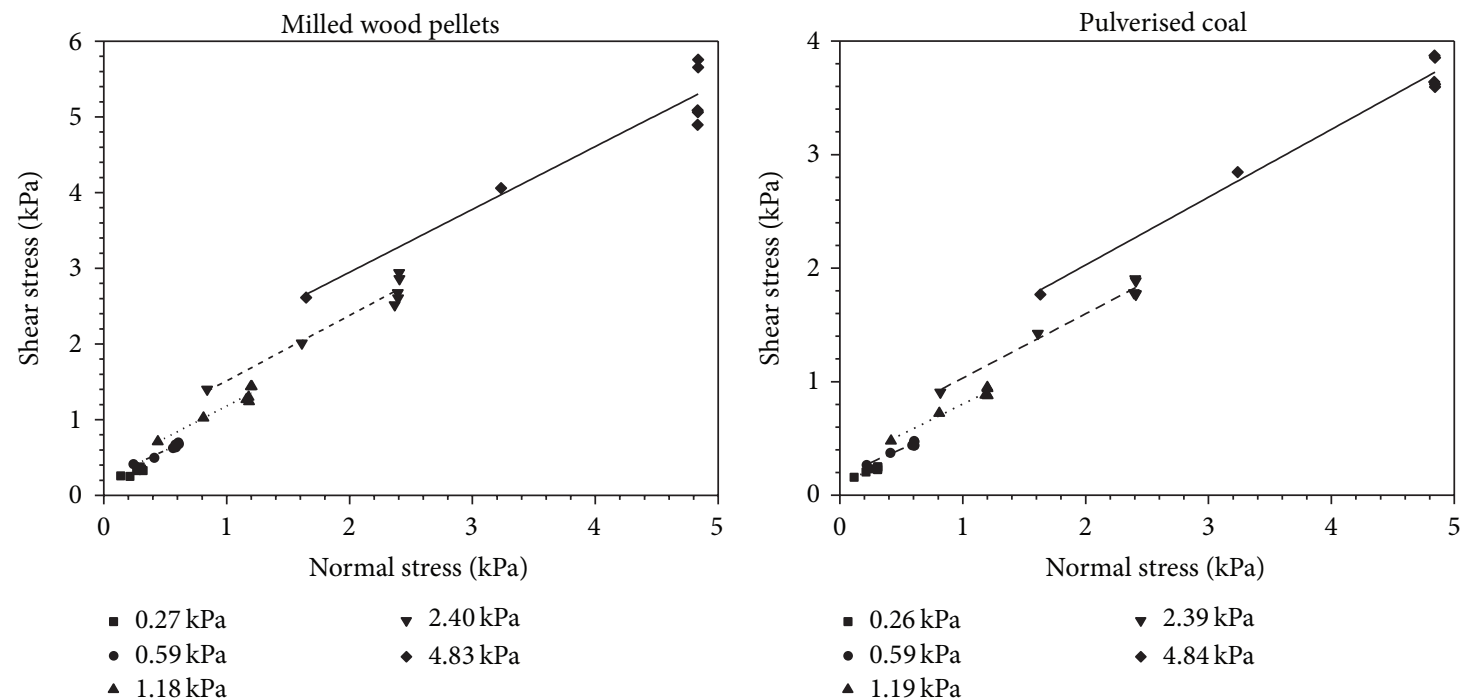

FIgURE 2: Family of yield loci for each material. 

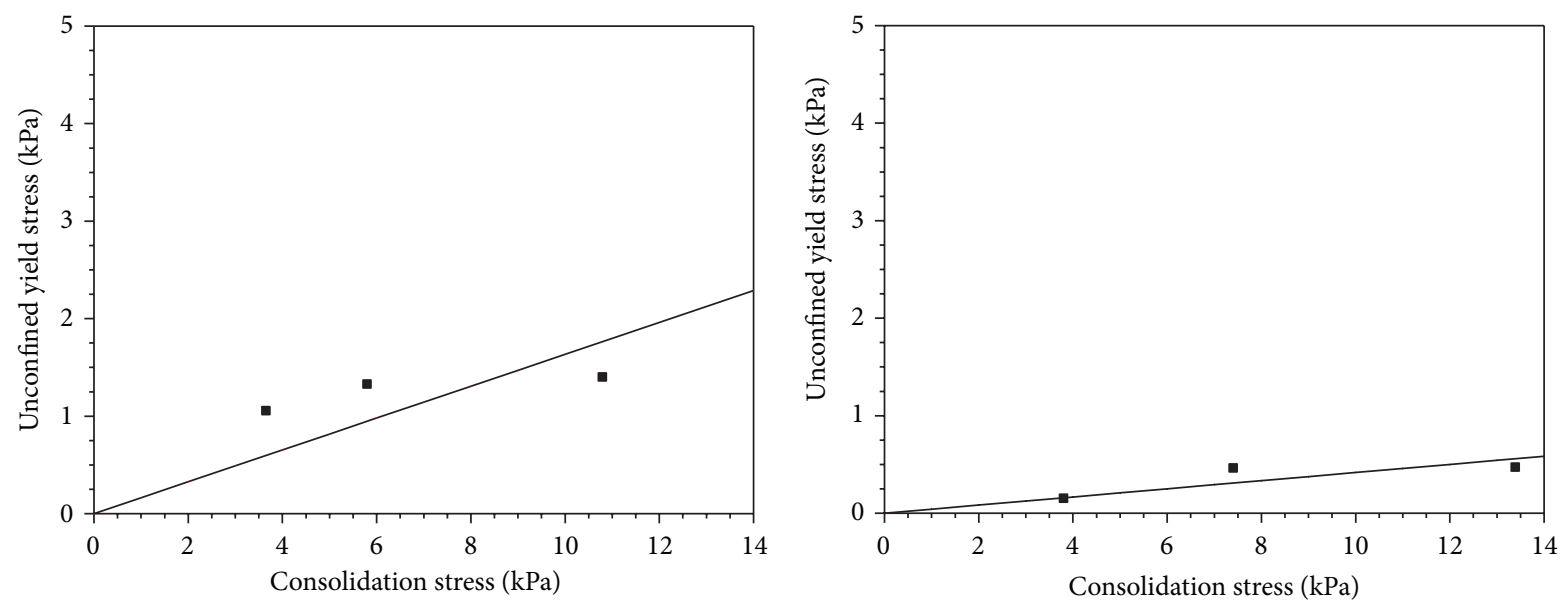

- Wood pellets

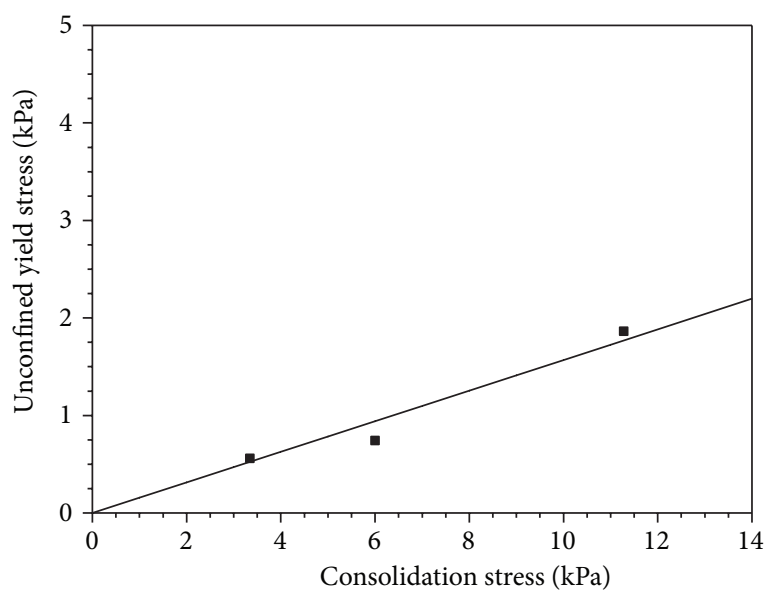

- Ground anthracite

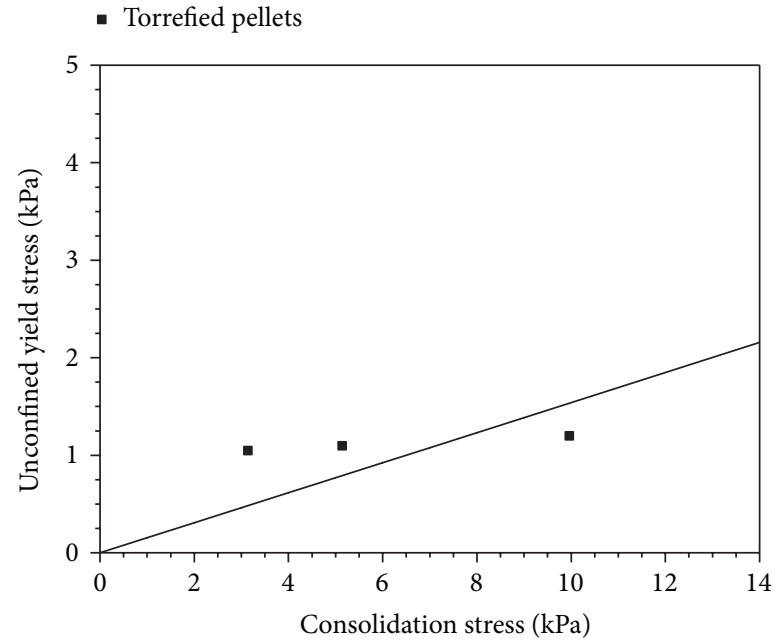

- Torrefied wood chips

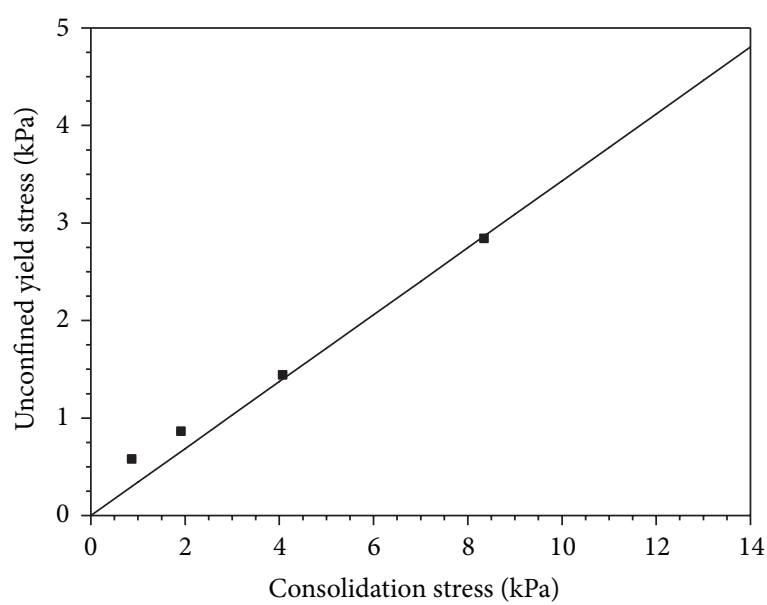

- Milled wood pellets

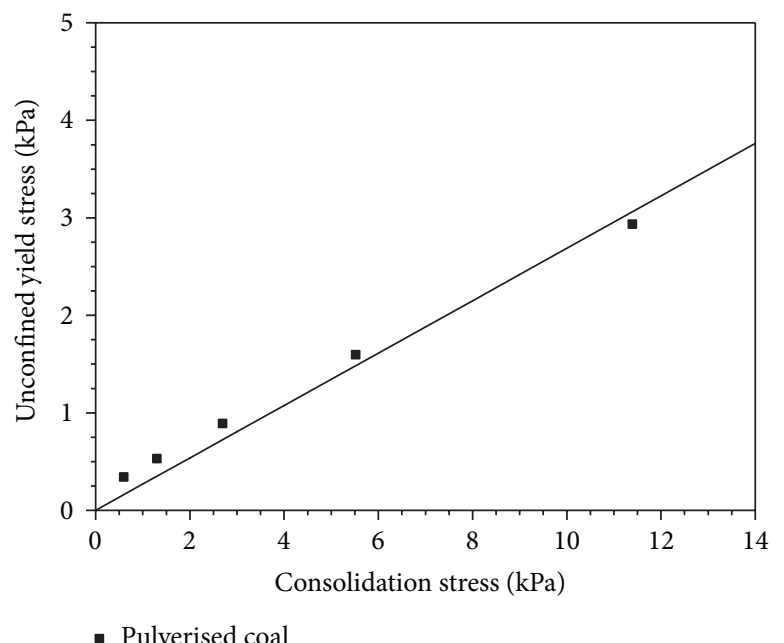

FIgURE 3: Material flow function for each material.

when compared to the remaining materials. It is observed from Figure 5 that for both of the fine materials, little distinction can be made between either the stainless steel or mild steel (dry). Both materials generate a wall friction angle of approximately $10^{\circ}$ in the case of the milled wood pellets and $30^{\circ}$ in the case of the pulverised coal. Further to this, a similar wall friction angle to the mild/stainless steel is recorded for the TIVAR 88 in the case of the pulverised coal. 

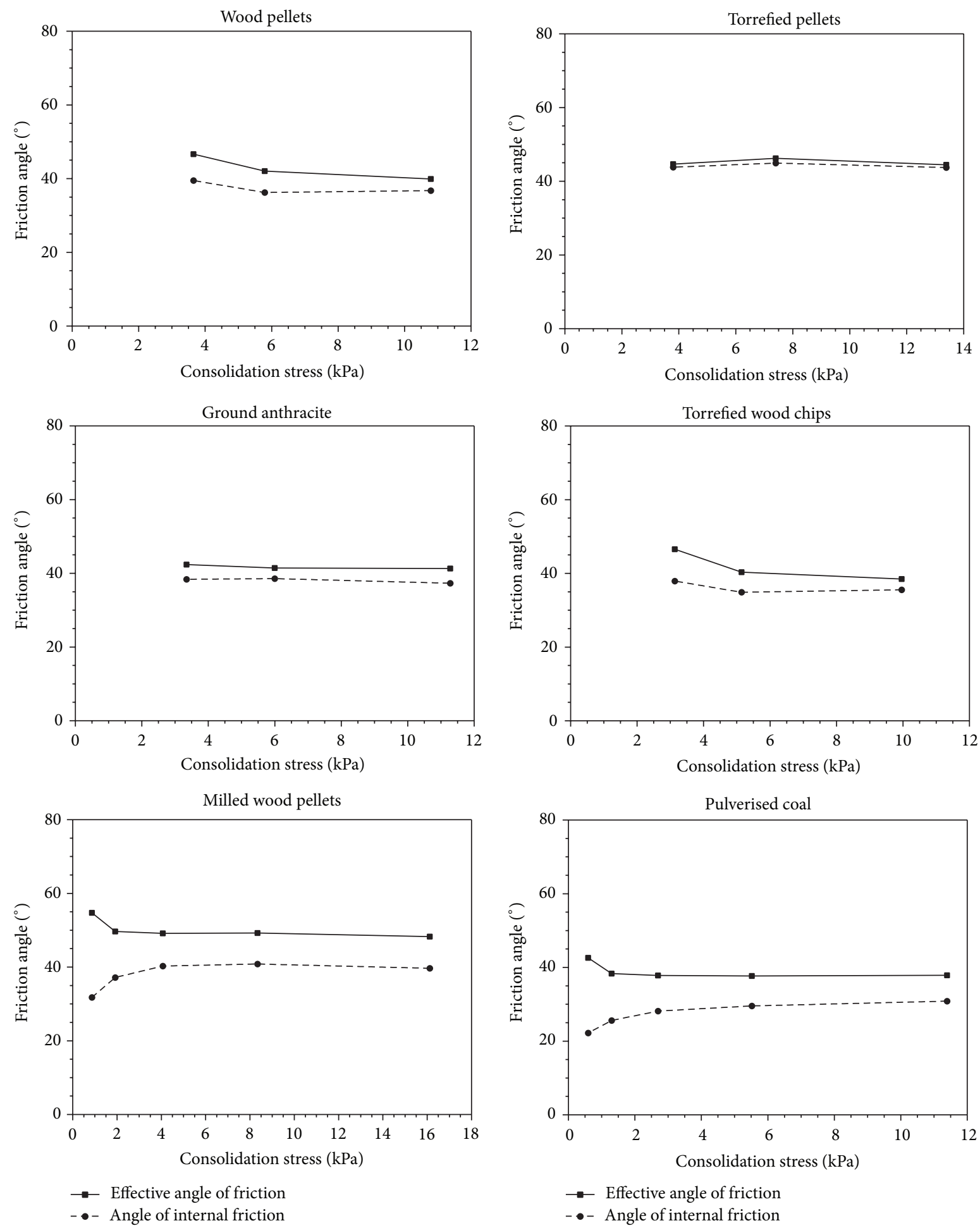

FIGURE 4: Effective angle of internal friction and angle of internal friction with varying consolidation stress.

Comparatively, the milled wood pellets require a far larger wall friction angle when used in conjunction with the TIVAR 88. This is due to enhanced electrostatic forces being present. During testing, electrostatic forces between the TIVAR 88 sample and the milled wood pellets were noticeable with the milled wood pellets showing attraction to the TIVAR 88 sample prior to testing.

The wood pellets, torrefied pellets, and torrefied wood chips display similar wall friction angles for all wall material samples. Values of approximately $30^{\circ}$ are recorded for both 

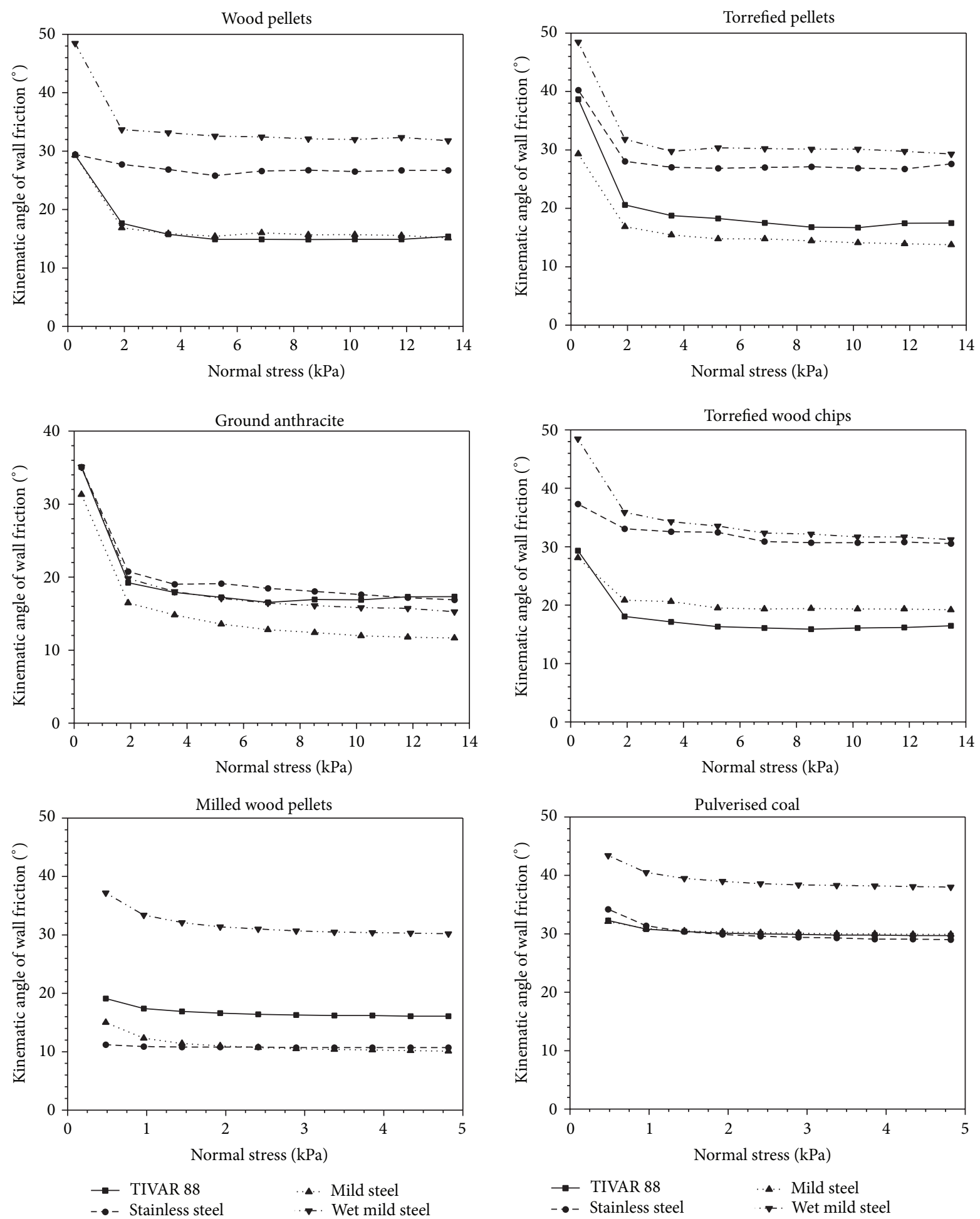

FIGURE 5: Kinematic angle of wall friction with varying normal stress.

wet mild steel and stainless steel and between $15^{\circ}$ and $20^{\circ}$ for dry mild steel and TIVAR 88, where normal stresses in excess of $2 \mathrm{kPa}$ are generated. Ground anthracite coal presents an anomaly, recording lower friction angles with all wall material samples. The anthracite coal has a hard and smooth surface and thus inherently has a lower coefficient of friction than any of the remaining coarse materials. Further to this, as the particle size is significantly larger than the pulverised coal, the bulk solid is able to hold its shape more readily and slide freely over the wall material.

Comparing the milled wood pellets with the pulverised coal, it can be seen from Figure 5 that a far steeper hopper 
TABLE 3: Hopper half angle for all fuels using TIVAR 88, stainless steel, and mild steel as wall materials.

\begin{tabular}{lcccc}
\hline Material & \multicolumn{3}{c}{ Hopper half angle $\left(^{\circ}\right.$ ) } & Wet mild steel \\
\hline Wood pellets & 33 & Stainless steel & Mild steel & 10 \\
Torrefied wood pellets & 29 & 17 & 34 & 15 \\
Ground anthracite & 31 & 17 & 34 & 34 \\
Torrefied wood chips & 32 & 31 & 38 & 11 \\
Milled wood pellets & 31 & 12 & 28 & 14 \\
Pulverised coal & 13 & 37 & 38 & 0 \\
\hline
\end{tabular}

angle is required to prompt flow when handing the pulverised coal. Comparing values for both the mild and stainless steel, a difference of approximately $20^{\circ}$ is observed between the milled wood pellets and the pulverised coal. Such differences take place due to the respective particle size of the materials. Pulverised coal presents a far lower mean particle size when compared to the milled wood pellets. As the particle size of a material decreases, more particles are allowed to interact with the wall material. An approximate relationship between the number of particle contacts and particle diameter is

$$
n \propto \frac{A}{d_{p}^{2}}
$$

where $n$ is the number of particle contacts, $A$ is the bulk area that those particles occupy $\left(\mathrm{m}^{2}\right)$, and $d_{p}$ is the particle diameter $(\mathrm{m})$ [18]. In the case of the pulverised coal and the wall friction shear test, a decrease in particle size brings about an increase in friction due to the increase in the number of particle contacts. Therefore, it is the decrease in particle size that leads to the increase in the kinematic angle of wall friction compared to the milled wood pellets.

3.3. Hopper Half Angle and Minimum Outlet Diameter. When designing a hopper for storing and feeding a bulk solid, a series of hopper flow factor plots developed by Jenike detailed in Bulletin number 123 [11, 21] can be used. Such plots allow both the hopper half angle and the hopper flow factor to be determined where both parameters are associated with either the mass flow or funnel flow regime. Plotting the inverse of the hopper flow factor on the plots for the material flow function and taking the point of intersection generates a critical stress for flow. From both of these parameters the minimum outlet diameter of a hopper can be determined. The following relationships are for a conical hopper:

$$
\begin{gathered}
B=\frac{H(\theta) \sigma_{\text {crit }},}{\rho_{b} g} \\
H(\theta)=2.0+\frac{\theta}{60},
\end{gathered}
$$

where $B$ is the minimum hopper outlet diameter $(\mathrm{m}), \theta$ is the hopper half angle $\left({ }^{\circ}\right), \sigma_{\text {crit }}$ is the critical stress $\left(\mathrm{N} / \mathrm{m}^{2}\right), \rho_{b}$ is the bulk density $\left(\mathrm{kg} / \mathrm{m}^{3}\right)$, and $g$ is the gravitational acceleration constant $\left(9.81 \mathrm{~m} / \mathrm{s}^{2}\right)$ [11].
Table 3 shows TIVAR 88 and mild steel to require a similar hopper half angle for all bulk solids. Pulverised coal is observed to require the steepest hopper slope in all wall material cases, and the ground anthracite is broadly shown to require the same hopper half angle regardless of wall material type. All bulk solids highlight that where the mild steel wall material sample is wetted, a steeper hopper slope is required.

In the case of the wood pellets, torrefied pellets, ground anthracite, and torrefied wood chips, an intersection of the material flow function with the hopper flow factor does not occur in the stress range measured. This is due to the easyflowing nature of the coarse bulk solids. As a consequence, a critical stress for flow cannot be determined and in turn neither can a minimum outlet diameter for a conical hopper. Where this is found, the general rule of sizing the outlet diameter to a value of 10 to 12 times the average particle diameter $\left(d_{p}\right)$ can be applied. This general rule is usually sufficient to prompt flow unaided [22, 23]. In the case of coarse bulk solid materials, sizing the outlet as such primarily seeks to counter flow problems caused by the formation of mechanical bridges.

Table 4 provides an overview of the minimum outlet diameter required for a conical hopper for both the milled wood pellets and the pulverised bituminous coal. The outlet diameter is expressed as a multiple of the average particle diameter for each fuel and as such the values can be directly compared to the general rule stated to determine the outlet diameter when feeding coarse fuels (i.e., 10 to 12 times the average particle diameter).

3.4. Energy Requirement of the HLH. Each of the hoppers used in the experimental setup of the HLH has an outlet diameter of $76 \mathrm{~mm}$ and a hopper half angle of $28.5^{\circ}$. While this diameter is smaller than any of those stated in Table 4, it was found that the limiting factor in the construction of the HLH was the valve diameter due to the operating pressures required for use. Experimental tests with all fuels highlighted that only the wood pellets, torrefied wood pellets, and ground anthracite grains were able to flow unaided. As indicated by Table 4 , the torrefied wood chips, milled wood pellets, and pulverised coal were found to be incompatible with the valve diameter used in the HLH and were not found to flow unaided. Therefore, experimental tests in conjunction with the HLH were only taken further with the wood pellets, torrefied wood pellets, and ground anthracite grains. Feeding took place against a back pressure of 25 barg in both Mode 1 
TABLE 4: Minimum outlet diameter as a multiple of average particle diameter $\left(d_{p}\right)$ for a conical hopper containing milled wood pellets and pulverised bituminous coal using TIVAR 88 , stainless steel, and mild steel as wall materials.

\begin{tabular}{lcccc}
\hline \multirow{2}{*}{ Material } & & \multicolumn{2}{c}{ Minimum hopper outlet diameter/d } & \\
& TIVAR 88 & Stainless steel & Mild steel & Wet mild steel \\
\hline Milled wood pellets & 492 & 553 & 557 & 418 \\
Pulverised coal & 582 & 614 & 582 & 495 \\
\hline
\end{tabular}

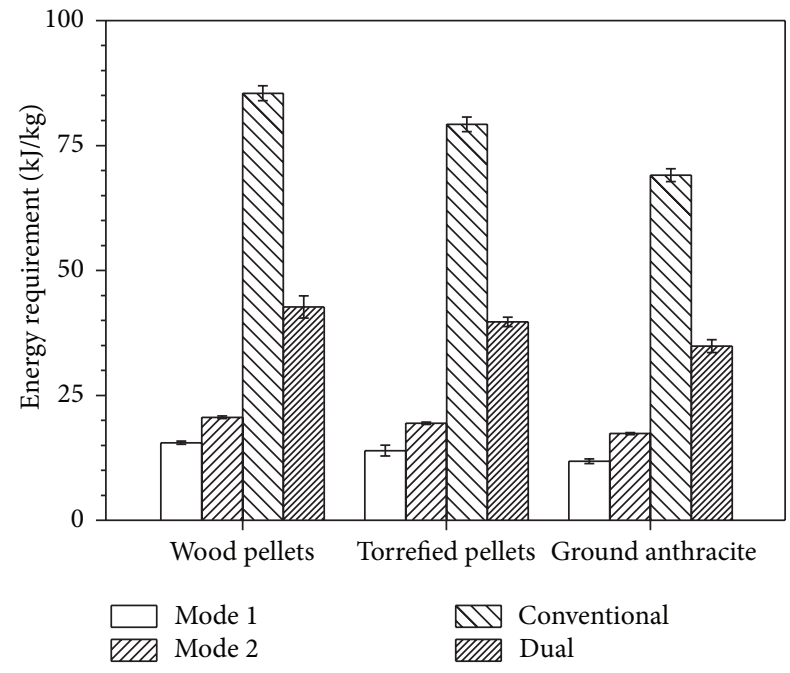

Figure 6: Energy requirement of the HLH (Mode 1 and Mode 2), a conventional single lock hopper and a dual lock hopper.

and Mode 2. A mass per batch of $4 \mathrm{~kg}, 4.25 \mathrm{~kg}$, and $4.75 \mathrm{~kg}$ was used in the case of the wood pellets, torrefied pellets, and ground anthracite grains, respectively.

In addition to the HLH being operated in Mode 1 and Mode 2, the HLH was operated as a conventional single and dual lock hopper to provide a to-scale comparison to a widely deployed high pressure feed system. Both systems (single and dual lock hopper) were operated using a threestage compressor in the compression stage, and thus the energy requirements for all systems (HLH, single and dual lock hopper) were determined experimentally.

Referencing Table 1 and assessing the particle density of each of the materials alongside the mass per batch of fuel fed, it is observed that the void space present in the top hopper varies from fuel to fuel. An approximate void space of $5350 \mathrm{~mL}, 5160 \mathrm{~mL}$, and $5010 \mathrm{~mL}$ is present for the wood pellets, torrefied pellets, and ground anthracite grains, respectively.

Figure 6 shows a trend of decreasing energy use with decreasing void space. Although the results shown in Figure 6 assess the energy use on a mass basis and in turn are inclusive of each respective mass per batch, a decreasing trend of volume of water pumped in the compression stage of Mode 1 is also observed with decreasing void space. This translates to a trend of decreasing raw energy use with decreasing void space. The volume of water pumped in Mode 2 is maintained constant, and the decreasing trend shown in Figure 6 is solely accounted for by the difference in mass per batch between fuels.
Mode 1 is seen to generate a higher energy saving compared to Mode 2 in all cases and the greatest energy saving comes when feeding the ground anthracite coal in Mode 1 compared to a conventional single lock hopper. This is followed by the torrefied pellets and then the standard wood pellets. This trend is observed due to the smaller void space present in the top hopper prior to feeding when operating with the ground anthracite compared to the two pelletised fuels and in turn the lower energy requirement by the high pressure water pump operating in Mode 1. Although this also affects both types of conventional lock hopper as this means a smaller volume of gas has to be compressed; energy saving is relative and so this benefit does not translate to a decrease in energy saving.

Comparatively, this benefit is not felt when both the conventional and dual lock hopper are compared to Mode 2. As the energy required by the high pressure water pump remains constant for all fuels in Mode 2, it is only the mass per batch that affects the energy required per unit mass fed. The reduction in void space presented by the torrefied pellets over the standard wood pellets and in turn the ground anthracite over the torrefied pellets does not constitute an advantage for Mode 2, whereas it does for both a conventional and a dual lock hopper. Figure 7 shows energy savings to drop for both the torrefied pellets and the ground anthracite coal compared to the standard wood pellets due to the reduction in void space. It can be concluded from Figure 7 that the greatest energy savings are generated in Mode 1 where the void space present between the fuels is minimised, and where the void space between the fuels is maximised in the case of Mode 2.

3.5. Effect of the HLH on Fuel Moisture Content. It is important to examine the effect the HLH has on the moisture content of the fuel due to the inherent use of water in the system. The effect of wet conditions can be very significant due to the formation of interparticle liquid bridges. This is especially true where moisture unstable fuels are being fed, as slight changes in moisture content can dramatically alter a fuel's physical properties and promote flow problems. Therefore, analysing the effect the HLH has on the moisture content of a fuel being fed allows an assessment to be made regarding the compatibility of a feedstock with the system.

Moisture content variations were analysed using wood pellets as the primary feedstock as wood pellets present an absorbent fuel able to most accurately monitor moisture uptake brought about during feeding. Moisture content was assessed assuming that any mass increase across the pressure boundary was due to the uptake of water by the pellets and so the mass of each batch of wood pellets was assessed before and after feeding was completed. Table 5 provides an 


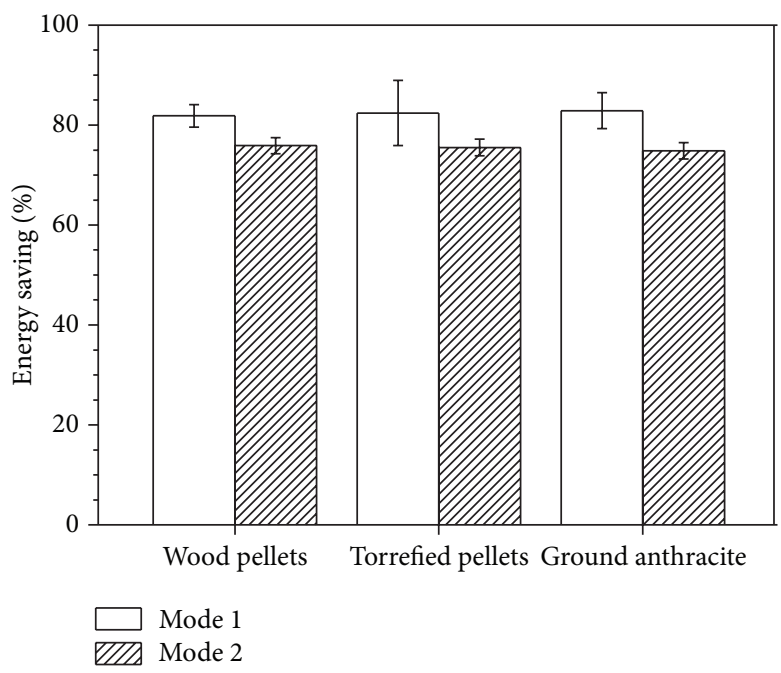

(a)

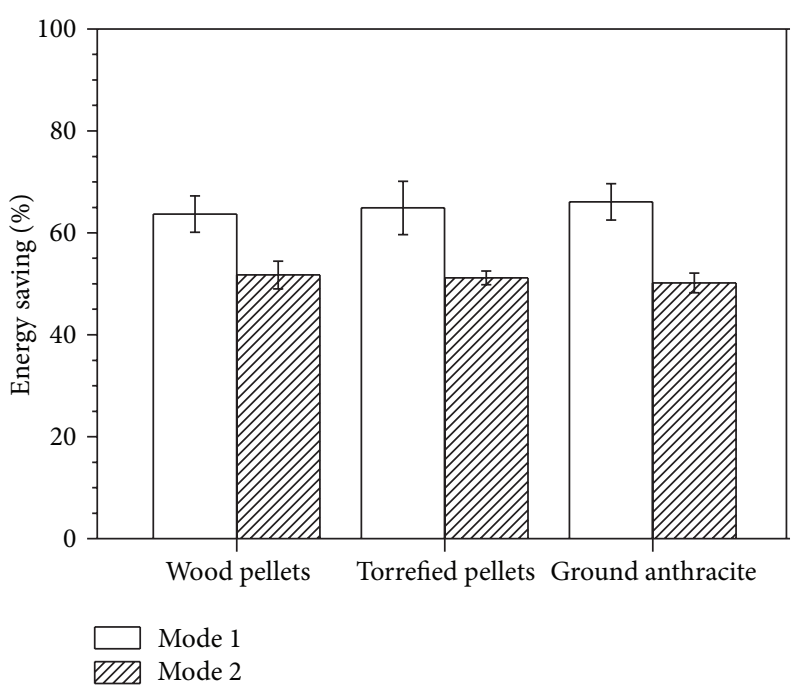

(b)

FIGURE 7: Energy saving generated by the HLH operating in Mode 1 and Mode 2 compared to a conventional single lock hopper (a) and a dual lock hopper (b).

TABLE 5: Effect of the HLH on the moisture content of wood pellets.

\begin{tabular}{lcc}
\hline \multirow{2}{*}{ Pressure (barg) } & \multicolumn{2}{c}{ Moisture content increase (\%) } \\
& Mode 1 & Mode 2 \\
\hline 10 & $0.37 \pm 0.25$ & $0.54 \pm 0.21$ \\
15 & $0.27 \pm 0.03$ & $0.81 \pm 0.22$ \\
20 & $0.31 \pm 0.12$ & $0.22 \pm 0.01$ \\
25 & $0.60 \pm 0.07$ & $0.50 \pm 0.37$ \\
\hline
\end{tabular}

overview of the changes in moisture content recorded while operating the $\mathrm{HLH}$ at a range of operating pressures.

It can be seen from Table 5 that moisture content increases are relatively stable across both modes of operation and are recorded to be less than $1 \mathrm{wt} \%$ for all operating pressures. No direct relationship between operating pressure and moisture content increase is observed, and it is proposed that any moisture taken up by the fuel is due to residual moisture present on the hopper walls. Therefore, it is anticipated that as the HLH is scaled up, increases in the overall moisture content will be reduced. However, it is important to state that local effects will remain the same in all cases.

In addition to work with wood pellets, moisture content increases were also recorded when feeding torrefied wood pellets and ground anthracite grains. Measurements were taken for an operating pressure of 25 barg and during operation in Mode 1. Moisture contents were found to increase by approximately $0.2 \%$ and $0.6 \%$ when feeding torrefied wood pellets and ground anthracite grains, respectively.

\section{Conclusions}

The Jenike design procedure was explored for a broad range of materials with varying particle size and shape for use in new high pressure solids feed system, the Hydraulic Lock Hopper. Large scale shear testing equipment was used to quantify the interparticle friction effects of four coarse fuels: wood pellets, torrefied wood pellets, torrefied wood chips, and ground anthracite grains, and the Brookfield Powder Flow Tester was used in conjunction with two fine fuels: milled wood pellets and pulverised bituminous coal. Tests showed all of the coarse fuels to be either free-flowing or easyflowing materials, whereas both of the fine fuels were found to be cohesive. Wood pellets, torrefied wood pellets, and ground anthracite grains were successfully fed to pressures as high as 25 barg using the Hydraulic Lock Hopper, in two modes of operation. Energy savings in the region of $80 \%$ for Mode 1 and $75 \%$ for Mode 2 compared to a conventional lock hopper were consistently achieved while feeding all fuels. Energy savings were found to peak at $82.9 \%$ when feeding ground anthracite grains at a pressure of 25 barg in Mode 1 compared to a conventional lock hopper operating at the same pressure. In addition to this, it was found that the Hydraulic Lock Hopper has a negligible effect on the moisture content of the fuel being fed, with moisture content increases less than $1 \mathrm{wt} \%$ being recorded in all cases.

\section{Conflict of Interests}

The authors declare that there is no conflict of interests regarding the publication of this paper.

\section{Acknowledgments}

The authors gratefully acknowledge the Engineering and Physical Science Research Council (EPSRC) and the Biomass and Fossil Fuels Research Alliance (BF2RA) for their financial support. Special thanks go to ECN for supplying the torrefied material and to the Wolfson Centre for Bulk Solids Handling 
Technology for their guidance and use of their laboratory facilities. Thanks also go to Mike O'Meara and David Palmer (University of Sheffield) for their technical assistance in the construction of the experimental rig.

\section{References}

[1] G. Wiltsee, Lessons Learned from Existing Biomass Power Plants, National Renewable Energy Laboratory, West Sacramento, Calif, USA, 2000.

[2] S. van Loo and J. Koppejan, The Handbook of Biomass Combustion and Co-Firing, Earthscan, 2008.

[3] D. L. Bonk and A. Hay, Stamet Solids Pump Feeds Coal into 210 psig in a DOE Supported Project, Power-Gen America, Anaheim, Calif, USA, 1995.

[4] S. J. Clayton, G. J. Stiegel, and J. G. Wimer, Gasification Technologies: Gasification Markets and Technologies-Present and Future: An Industry Perspective, US-DOE, 2002.

[5] M. C. Huéscar, H. N. Phylaktou, G. E. Andrews, and B. M. Gibbs, Determination of the Minimum Explosible and Most Reactive Concentrations for Pulverised Biomass Using a Modified Hartmann Apparatus, Energy Research Institute, University of Leeds, Leeds, UK, 2012.

[6] C. H. Medina, H. N. Phylaktou, H. Sattar, G. E. Andrews, and B. M. Gibbs, "The development of an experimental method for the determination of the minimum explosible concentration of biomass powders," Biomass and Bioenergy, vol. 53, pp. 95-104, 2013.

[7] M. Merritt, "Biomass: energy remedy or safety headache?" The Chemical Engineer, no. 857, pp. 30-34, 2012.

[8] H. A. Janssen, "Tests on grain pressure silos," Zeitschrift des Vereines Deutscher Ingenieure, vol. 39, pp. 1045-1049, 1895.

[9] M. Sperl, "Experiments on corn pressure in silo cells-translation and comment of Janssen's paper from 1895," Granular Matter, vol. 8, no. 2, pp. 59-65, 2006.

[10] A. W. Jenike, Gravity Flow of Bulk Solids, Bulletin no. 108, Utah Engineering Experimental Station, University of Utah, Salt Lake City, Utah, USA, 1961.

[11] A. W. Jenike, "Storage and flow of solids," Bulletin No. 123, Utah Engineering Experimental Station, University of Utah, 1964.

[12] F. Miccio, D. Barletta, and M. Poletto, "Flow properties and arching behavior of biomass particulate solids," Powder Technology, vol. 235, pp. 312-321, 2013.

[13] M. R. Wu, D. L. Schott, and G. Lodewijks, "Physical properties of solid biomass," Biomass and Bioenergy, vol. 35, no. 5, pp. 2093-2105, 2011.

[14] N. Chevanan, A. R. Womac, V. S. P. Bitra, D. C. Yoder, and S. Sokhansanj, "Flowability parameters for chopped switchgrass, wheat straw and corn stover," Powder Technology, vol. 193, no. 1, pp. 79-86, 2009.

[15] P. Adapa, L. Tabil, and G. Schoenau, "Physical and frictional properties of non-treated and steam exploded barley, canola, oat and wheat straw grinds," Powder Technology, vol. 201, no. 3, pp. 230-241, 2010.

[16] D. Barletta, R. J. Berry, S. H. Larsson, T. A. Lestander, M. Poletto, and A. Ramírez-Gómez, "Can bulk solids best practice techniques for flow characterization and storage/handling equipment design be used reliably for biomass materials of different classes?" in Proceedings of the 7th International Conference for Conveying and Handling of Particulate Solids (CHoPS '12), Friedrichshafen, Germany, September 2012.
[17] M. J. Rhodes, Introduction to Particle Technology, Wiley, 2008.

[18] D. Schulze, Powders and Bulk Solids: Behavior, Characterization, Storage and Flow, Springer, New York, NY, USA, 2008.

[19] J. M. Craven, J. Swithenbank, V. N. Sharifi, D. Peralta-Solorio, G. Kelsall, and P. Sage, "Development of a novel solids feed system for high pressure gasification," Fuel Processing Technology, vol. 119, pp. 32-40, 2014.

[20] C. R. Woodcock and J. S. Mason, Bulk Solids Handling: An Introduction to the Practice and Technology, Chapman \& Hall, 1996.

[21] P. C. Arnold, A. G. Mclean, and A. W. Roberts, Bulk Solids: Storage, Flow and Handling, TUNRA Bulk Solids Handling Research Associates, 1982.

[22] K. Jacob, Bin and Hopper Design, The Dow Chemical Company, 2000.

[23] R. J. Berry, Personal Communication, The Wolfson Centre for Bulk Solids Handling Technology, University of Greenwich, 2013. 

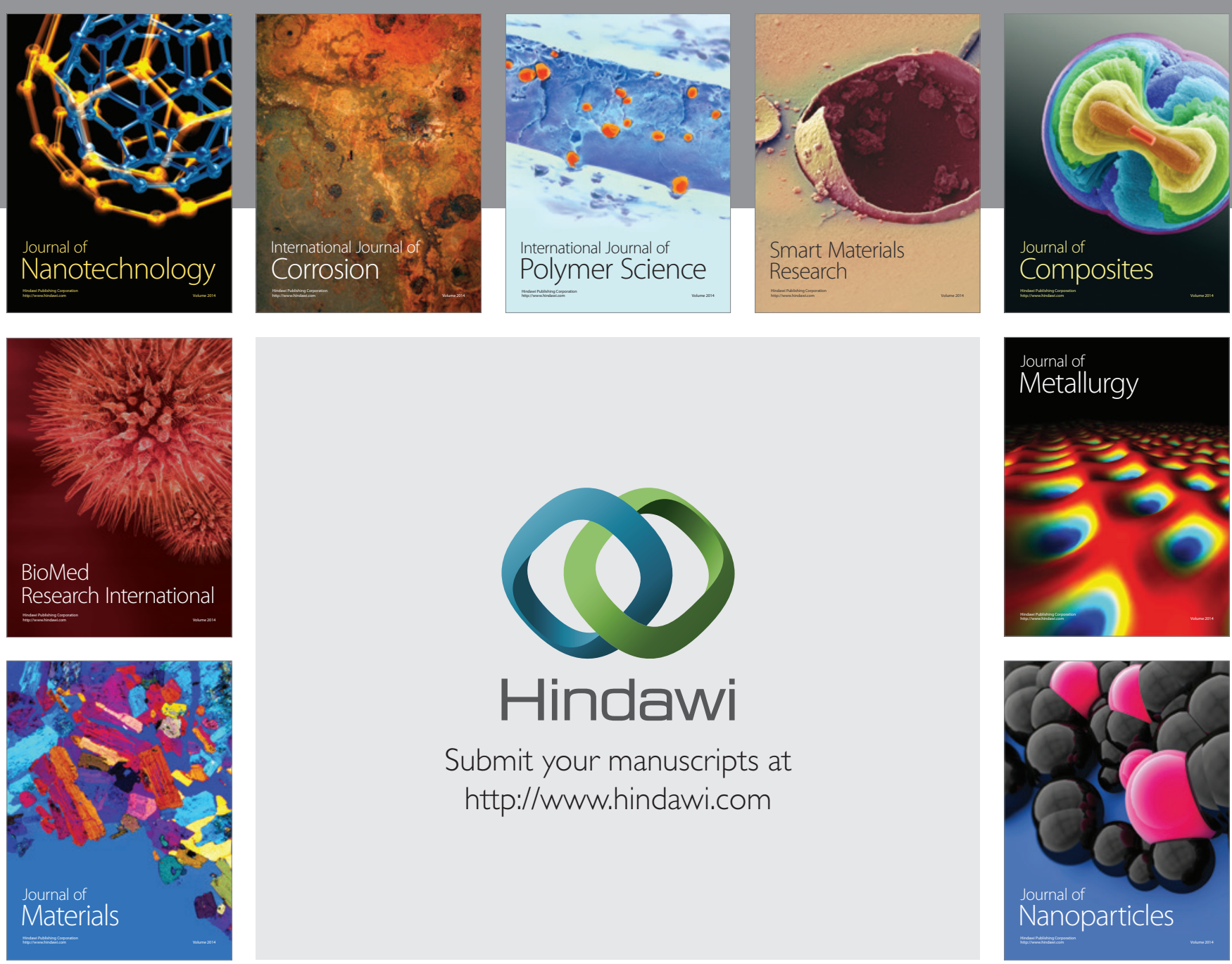

Submit your manuscripts at http://www.hindawi.com
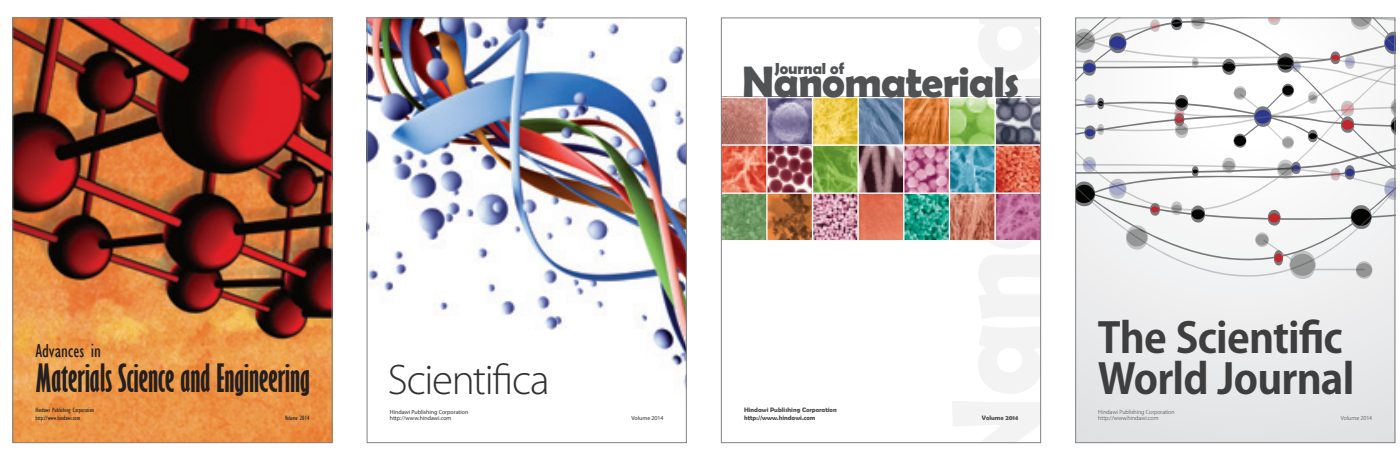

\section{The Scientific World Journal}
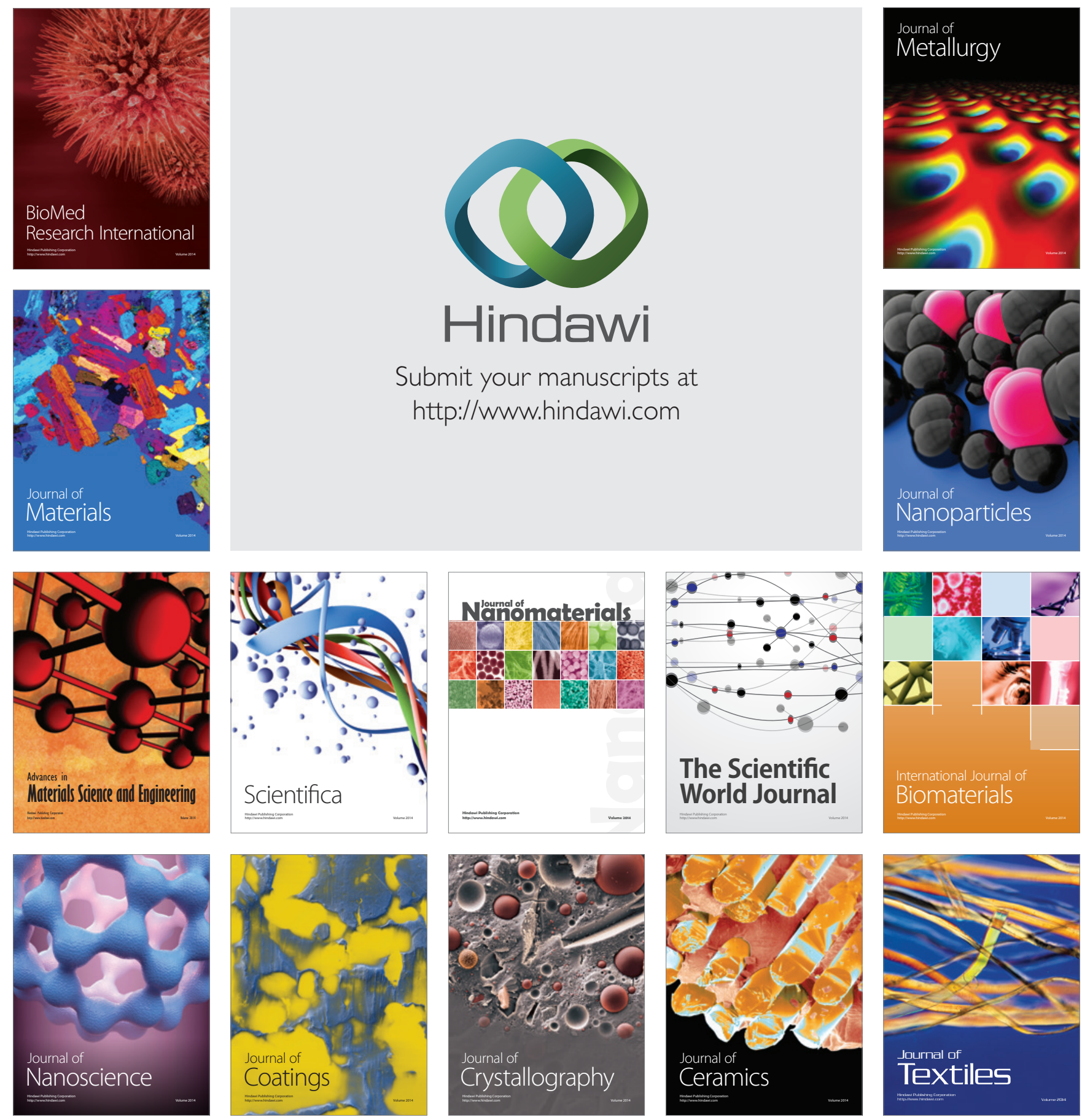